\title{
LATERAL EXPANSION REEFS AT MEXICO ROCKS PATCH REEF COMPLEX, BELIZE, CENTRAL AMERICA
}

MCHENRY, Theodore M.*; BURKE, Collette D.; BISCHOFF, William D.; MAZZULLO, Salvatore J.; HAWTHORNE, Jeralynne, Dept. of Geology, Wichita State University, Wichita, Ks 67260-0027, U.S.A.

Patch reefs in Belize, have developed on a partially enclosed south sloping ramp leeward of the barrier reef. Mexico Rocks is a large areally extensive patch reef complex on the northern outer shelf of this ramp. Analysis of 25 patch reefs at Mexico Rocks indicates that they are less than 3500 years old, virtually monospecific (composed of $83 \%$ Montastrea annularis, the major framework builder), and exhibit no lateral biotic zonation caused by differential wave energy. Based on Spearman correlation coefficients, coral species richness of individual patch reefs within Mexico Rocks increases with proximity to a linear Pleistocene bedrock high, increasing areal size, and increasing framework degradation and cavity formation. In general, the larger reefs in Mexico Rocks have greater amounts of bio- and physical degradation and greater amounts of cavity development. These factors combine to increase the spatial heterogeneity or habitat complexity of the reefs by producing subenvironments that can be colonized by cryptobionts and shelter fragile coral species.

In addition, non-constant sum unmixing analyses indicate that three types of reefs can be classified within the complex. Type 1 reefs are relatively large, high diversity reefs that occur predominately on the high bedrock trend. Type 2 are medium size and diversity patch reefs that also occur on this trend, whereas Type 3 reefs are all small, monospecific reefs dispersed throughout the complex. These 3 reef types have been used to develop environmentally sound recommendations for usage zonation of Mexico Rocks as it is earmarked for reservation status by the Belizean government.

During October, 1995 NOAA (press release 95-80) announced reports of coral bleaching found in Belize for the first time. The extent of coral bleaching as a result of the 1995 event quantitatively will be assessed in the Mexico Rocks complex using this pre-existing base line study as a source of comparison. 